\title{
Imigração, identidade e multiculturalismo nas organizações brasileiras
}

\author{
Immigration, identidy and multiculturalism in brazilian organizations
}

\section{Immigration, dans le multiculturalisme et identité des organisations brésilien}

\author{
Inmigración, identidad y multiculturalismo en las organizaciones brasileñas
}

\author{
Lisiane Selaimen Heemann Ketzer ${ }^{1}$ \\ Julice Salvagni ${ }^{2}$ \\ Andrea Poleto Oltramati ${ }^{2}$ \\ Daiane Boelhouwer Menezes ${ }^{3}$
}

Recebido em 31/07/2017; revisado e aprovado em 20/12/2017; aceito em 27/12/2017

DOI: http://dx.doi.org/10.20435/inter.v19i3.1673

\begin{abstract}
Resumo: Este artigo problematiza, com base na análise de entrevistas individuais, a identidade do imigrante no Brasil e a forma como o multiculturalismo é abordado no país por meio das organizações de trabalho. A identidade é entendida como uma construção social em constante transformação, acentuada no momento em que os indivíduos migram, dado o encontro com as diferenças. Essa identidade social é composta pelos costumes e tradições de sua nação e, ao migrar, a falta dessas questões é perceptível na vida do imigrante. Como resultados, destaca-se que os motivos para migrar hoje em dia são semelhantes aos do passado, como melhorar de vida e fugir de problemas econômicos, religiosos e sociais. No Brasil, o racismo e a exclusão social ainda são presentes mesmo que este seja um país multicultural. Na esfera das organizações, o multiculturalismo está recém iniciando, e verifica-se que a diversidade é questionada e que ainda existem preconceitos devido à diferença cultural do indivíduo.
\end{abstract}

Palavras-chave: identidade social; imigrantes; multicultural; multiculturalismo.

Abstract: This paper discusses, based on the analysis of individual interviews, the identity of the immigrant in Brazil and the way multiculturalism is approached in the country through the working organizations. Identity is understood as a social construction in constant transformation, accentuated at the moment when individuals migrate given the encounter with the differences. This social identity is made up of the customs and traditions of their nation, and when migrating, the lack of such things is perceivable in the life of the immigrant. As a result, it stands out that the reasons for migrating nowadays are similar to those of the past, such as improving life and getting away from economic, religious and social problems. In Brazil, racism and social exclusion are still present even if it is a multicultural country. In the sphere of organizations, multiculturalism is just beginning, and it turns out that diversity is questioned and that there are still prejudice due to the cultural difference of the individual.

Keywords: social identity; immigrants; multicultural; multiculturalism.

Résumé: Cet article traite, basé sur l'analyse des entretiens individuels, l'identité de l'immigré au Brésil et comment le multiculturalisme est abordée dans le pays par le travail des organisations. L'identité est considérée comme une construction sociale en constante transformation, a marqué le moment où les individus migrent, comme la rencontre avec les différences. Cette identité sociale se compose des coutumes et traditions de leur nation et de migration, l'absence de ces questions est évidente dans la vie des immigrants. En conséquence, il est souligné que les raisons de migrer aujourd'hui sont semblables à celles du passé comme une vie meilleure et d'échapper à des problèmes économiques, sociaux et religieux. Au Brésil, le racisme et l'exclusion sociale sont toujours présents, même si elle est un pays multiculturel. Dans le domaine des organisations, le multiculturalisme ne fait que commencer, et il se trouve que la diversité est remise en question et les préjugés qui existent encore en raison de la différence culturelle de l'individu.

Mots-clés: identité sociale; les immigrants; multiculturel; multiculturalisme.

Resumen: Este artículo problematiza, con base en el análisis de entrevistas individuales, la identidad del inmigrante en Brasil y la forma en que el multiculturalismo es abordado en el país a través de las organizaciones de trabajo. La identidad es entendida como una construcción social en constante transformación, acentuada

\footnotetext{
${ }^{1}$ Centro Universitário Ritter dos Reis, Porto Alegre, Rio Grande do Sul, Brasil.

2 Universidade Federal do Rio Grande do Sul (UFRGS), Porto Alegre, Rio Grande do Sul, Brasil.

3 Universidade do Vale do Rio dos Sinos (UNISINOS), São Leopoldo, Rio Grande do Sul, Brasil.
} 
en el momento en que los individuos migran, dado el encuentro con las diferencias. Esta identidad social está compuesta por las costumbres y tradiciones de su nación y, al migrar, la falta de esas cuestiones es perceptible en la vida del inmigrante. Como resultados, se destaca que los motivos para migrar hoy en día son similares a los del pasado, como mejorar de vida y huir de problemas económicos, religiosos y sociales. En el Brasil, el racismo y la exclusión social todavía son presentes aunque éste sea un país multicultural. En la esfera de las organizaciones, el multiculturalismo está recién comenzando, y se verifica que la diversidad es cuestionada y que todavía existen prejuicios debido a la diferencia cultural del individuo.

Palabras clave: identidad social; inmigrantes; multicultural; multiculturalismo.

\section{INTRODUÇÃO}

Este artigo apresenta a forma com que a identidade social de imigrantes estrangeiros no Brasil vem sendo percebida por eles próprios nas organizações de trabalho e na sociedade de modo geral. O ambiente profissional no qual refugiados e imigrantes econômicos estão inseridos é modificado em função da interlocução com estrangeiro, seja devido à língua, às diferenças culturais ou à construção/desconstrução de estereótipos que levam à sustentação das percepções das diferenças culturais. Tendo o Brasil figurado como importante destino de migrações nas últimas duas décadas (BAENINGER, et al, 2017), o debate sobre o assunto torna-se primordial para a sustentação de possíveis políticas migratórias de âmbito social ou organizacional, afora trazer à tona elementos das relações de trabalho que dizem respeito à exclusão tanto pela raça quanto pela classe.

De acordo com Hall (2003), com multiculturalismo é preciso ter igualdade social e justiça racial. Porém acredita-se que o racismo ainda está presente mesmo em sociedades multiculturais e que, dentro das organizações, também existem preconceitos. Acredita-se que, da visão do imigrante e sua realidade, aflorarão questões de preconceito relativo à cor, religião e etnia, mesmo que a diversidade seja uma questão considerada e respeitada nas organizações.

As migrações humanas estão presentes na história da grande maioria dos povos, especialmente desde o "aprimoramento das tecnologias dos meios de transporte e de comunicação, as culturas começaram a interagir e a se fundir" (GARCEZ; OLIVEIRA, 2016). As pessoas migram por várias razões, como guerras, repressão política, violência, pobreza, visando a possibilidade de melhoria de vida para si e para suas famílias (HALL, 2003).

$\mathrm{Na}$ contemporaneidade, a imigração internacional e sua complexidade crescem a cada ano com, por exemplo, a consolidação e aumento do número de refugiados (FIALKOM, 2016). De acordo com informações do Departamento de Assuntos Econômicos e Sociais da ONU (DESA), em 2015, o número de migrantes internacionais alcançou a marca de 244 milhões, o que corresponde a 3,3\% da população mundial, sendo 20 milhões de refugiados. Em relação ao ano 2000, isso significa um aumento de $41 \%$.

O Brasil, por sua vez, que havia recebido cerca de cinco milhões de imigrantes entre 1819 e fins da década de 1940 - o que representava $10 \%$ da população do país -, estagnou por um longo período, recebendo somente refugiados, especialmente judeus, sírios, libaneses e palestinos. Porém, nas últimas duas décadas, houve crescimento: em 2000, os imigrantes representavam quase 96 mil, ao passo que, em 2014, eram mais de um milhão e cem mil. O Rio Grande do Sul (RS) apresenta a mesma tendência, embora com crescimento menor: de cerca de 17,5 mil passa para 43,5 mil (UEBEL, 2015).

Com esse cenário, é necessário verificar quais estratégias e políticas a sociedade e as organizações estão adotando em relação a essa realidade multicultural sob o contexto social 
e econômico em que forma de trabalho do imigrante se insere. Assim, a questão norteadora desta pesquisa é: De que forma a identidade cultural vem sendo problematizada frente à imigração no multiculturalismo organizacional? Como há fatores culturais (modo de se vestir, de se portar, língua falada, etc.), religião e etnia diferentes nos imigrantes, além das diferenças de conhecimento e educação, acredita-se que esses fatores precisam ser vistos e respeitados em organizações multiculturais, pois entende-se que "falar em imigração implica automaticamente em falar sobre cultura" (SARRIERA; PIZZINATO; MENESES, 2005, p. 6).

Nas relações multiculturais, é necessário ater-se à igualdade racial e justiça social, conforme já citado por Hall ( 2003). Mesmo com as considerações e respeito a essas questões, nesse âmbito costumam aflorar questões quanto a preconceitos diversos. A aceitação do diverso parte de uma transgressão das relações de poder que estão contidas em especial no que Sodré (2015) intitula de relação racial.

O objetivo geral desta pesquisa é verificar como a identidade social e cultural dos imigrantes é problematizada no multiculturalismo organizacional na capital do RS, Porto Alegre. Os objetivos específicos são: analisar a elaboração da identidade social dos imigrantes com base nas suas narrativas de inserção social no Brasil e identificar a percepção dos imigrantes frente ao mercado profissional, destacando aspectos específicos acerca do trabalho do imigrante. Para tanto, primeiramente são discutidas as questões de migração, identidade, multiculturalismo e globalização e, posteriormente, são analisadas as falas de imigrantes entrevistados para a pesquisa.

\section{MIGRAÇÕES, IDENTIDADE, MULTICULTURALISMO E GLOBALIZAÇÃO}

A identidade social do sujeito é o âmago para a construção de qualquer identidade cultural e nacional. Essa identidade é formada por diversos fatores de um indivíduo já inserido em um contexto histórico-social que o precede, estando ainda sempre em transformação (HALL, 2000). Para Woodward (2000), a identidade é relacional uma vez que uma identidade depende da outra identidade que é diferente para existir, ou seja, de algo fora dela, que fornece as condições para que ela exista.

A visão de que a identidade seja unificada e coerente, mas que o sujeito moderno apresenta uma identidade deslocada, é uma forma simplista de descrever o sujeito de hoje. Entende-se que a identidade do sujeito não é algo inato, não é engessada, formada e estática, ela é construída ao longo do tempo; tal como Jacques (2006, p. 155) refere, é um "constante estar sendo", que se funda tanto por meio da igualdade quanto da diferença em relação aos outros. O sujeito assume identidades diferentes, pois é influenciado pelo momento em que vive. Assim, a identidade completa, unificada, segura e coerente é uma fantasia, uma vez que a afirmativa que a identidade possa ser 'deslocada' tornou-se um modo não aprofundado (HALL, 1997; 2000; 2003) de perceber o sujeito contemporâneo em relação as organizações.

Ao processo de identificação, entende-se que este "opera por meio da différance, ela envolve um trabalho discursivo, o fechamento e a marcação de fronteiras simbólicas, a produção de 'efeitos de fronteira" (HALL, 2000, p. 106). As identificações, assim, podem ir ao encontro da identidade do sujeito ou diferenciar-se por completo. Nesse jogo de reconhecimento é que a identidade vai se criando, e isso faz com que a produção de identificações não seja algo lógico e determinado. O processo de identificação, ou de diferenciação, será fundamental para a compreensão da formação das identidades. A identidade será coletivamente constituída por essas identificações, através do discurso, muito embora o ego ideal seja "composto de identificações 
com ideais culturais que não são necessariamente harmoniosos" (HALL, 2000, p. 107). Sobre o processo de formação de identidades, importante também ressaltar que os diferentes espaços de trabalho vão se constituir em oportunidades diferenciadas para a aquisição de atributos qualificativos da identidade do trabalhador e, por vezes, podem tanto qualificar quanto desqualificar os modos de ser dos sujeitos trabalhadores (JACQUES, 2006).

A construção de uma identidade está inteiramente conectada a uma comunidade simbólica, sendo essa, recorrentemente, uma nação. No mundo atual, as culturas nacionais em que se nasce ainda são uma das principais fontes de identidade cultural, outras dizem respeito à raça e etnia. Para Guimarães (2003), as raças devem ser estudadas somente quando se trata de identidades sociais. Pode-se dizer que a raça faz parte do discurso da origem e que "certos discursos falam de essências que são basicamente traços fisionômicos e qualidades morais e intelectuais; só nesse campo a ideia de raça faz sentido" (GUIMARÃES, 2003, p. 96). Esses discursos sobre as origens de um grupo, que usam termos que remetem à transmissão de traços fisionômicos, qualidades morais, intelectuais, psicológicas etc. remetem principalmente a relações de poder (PEREIRA; OLIVEIRA, 2017), especialmente pela discriminação do diverso e da hierarquização da sociedade brasileira em estruturas de poder e, sobretudo de classe (SODRÉ, 2017).

Quando se fala de lugares, discursos sobre lugares geográficos de origem (Brasil, Peru, Senegal, Haiti, etc.), fala-se também de etnia. Para Guimarães (2003), o conceito de etnia remete ao lugar de onde se veio e à identificação com um grande grupo de pessoas. A etnia não está impressa nos genes de uma pessoa, contudo pensa-se nela como se fosse parte da natureza essencial de uma pessoa. Todos esses fatores nutrem a construção da identidade de uma pessoa como indivíduo. De acordo com Hall (1997), a pessoa (sujeito) precisa se sentir parte de um lugar (país) para criar e ter sua identidade. Do contrário, ele experimentaria um profundo sentimento de perda subjetiva. A cultura nacional de uma pessoa é a principal fonte de identidade social, pois atua como foco de identificação para o indivíduo e como um sistema de representação - que é uma nação. Portanto é instigante conhecer o que ocorre com a identidade social de uma pessoa quando se muda para outra nação, ou, quando na sua própria nação, há indivíduos pertencentes a outras nações. Este é o retrato atual do sujeito pós-moderno marcado pela globalização, como os toxicômanos de identidade (ROLNIK, 1997).

Com a globalização, marcada pela facilidade de os sujeitos vincularem-se com outras culturas, criam-se, cada vez mais, sujeitos 'deslocados', pois a identidade de um indivíduo e a identidade cultural de um país é constituída também por outras culturas (MIRANDA, 2000). Assim, "as transformações associadas à modernidade libertam o indivíduo de seus apoios estáveis nas tradições e nas estruturas" (HALL, 1997, p. 25), possibilitando espaços híbridos com narrativas multiculturais. Assim, as identidades das sociedades atuais estão constantemente em transformação, as identidades nacionais "estão em declínio, mas novas identidades - híbridas - estão tomando seu lugar" (HALL, 1997, p. 69).

A vida social está mediada pelo mercado global de estilos, lugares, imagens, viagens internacionais, comunicação etc. Somos confrontados diariamente por uma gama de diferentes identidades, dentro das quais é possível fazer escolhas. Hall (1997) defende que isso difundiu o consumismo e que vivemos em um "supermercado cultural". Com isso, criou-se um fenômeno que o autor chama de "homogeneização cultural". Porém o autor argumenta que a constatação de que as identidades sociais são homogeneizadas é simplista, tornando-se um formato exagerado e unilateral. Da mesma forma que há o impacto da globalização, há o interesse pelo "local", 
por ser diferente dentro de uma cultura globalizada. Portanto é improvável que a globalização destrua as identidades nacionais, mas provável que produza, simultaneamente, novas identificações globais e novas identificações locais.

Após a segunda guerra mundial, o fenômeno da migração se intensificou. Um dos motivos que Hall (1997) ressalta para este fenômeno é a mensagem que o consumismo global transmitiu. Pessoas impulsionadas pela pobreza, fome, seca, guerra civil, subdesenvolvimento econômico, distúrbios políticos etc., acreditaram na mensagem de que há chances maiores de sobrevivência onde os "bens" são produzidos. Este foi um dos períodos mais longos e não planejados de emigração na história recente, facilitado pelo acesso ao ocidente, que, na era das comunicações globais, está a apenas a um voo de distância. Dessa forma, havia migrações contínuas e de grande escala, sendo estas legais ou ilegais. Como exemplo, podemos citar os latinos de países mais pobres (Haiti, Cuba, Porto Rico e República Dominicana) migrando para os Estados Unidos, o que acarretou uma mudança na mistura étnica do país. "Em 1995, previa-se que um terço dos estudantes de escolas públicas americanas seria constituído por não brancos" (CENSO DOS ESTADOS UNIDOS, 1991 apud HALL, 1997 ).

Há muitos outros exemplos, como os senegaleses na França e na Bélgica, os turcos e norte-africanos na Alemanha, os asiáticos (de ex-colônias holandesas) na Holanda etc. Essa fusão de etnia minoritária no interior dos estados-nação do ocidente levou à pluralização das culturas e identidades nacionais.

Para o subsecretário-geral do Departamento de Assuntos Econômicos e Sociais da ONU (DESA), Wu Hongbo, o aumento de imigrantes internacionais reflete a crescente importância da migração e tem se tornado uma parte integral das nossas economias e sociedades. A migração bem administrada traz importantes benefícios aos países de origem e destino, bem como para os migrantes e suas famílias. A agência da ONU para os refugiados afirma que esses são protegidos por leis internacionais. Eles saem de seus países por medo de perseguição, conflitos, violência e outras circunstâncias que perturbam seriamente a ordem pública. A situação dos refugiados é frequentemente tão intolerável que eles cruzam fronteiras para estarem em segurança e, ao serem reconhecidos como refugiados, passam a ter acesso à assistência do país em que se encontram. Para eles, é muito perigoso o retorno para casa, a ponto de a negação de asilo ter consequências que podem levar à morte. Essa situação é muito diferente da simples imigração voluntária, em que alguém decide cruzar fronteiras em busca de melhores oportunidades ou, ainda, da migração forçada, que diz respeito às pessoas que são deslocadas por motivos de desastres ambientais, fome etc. Porém essa última não é um conceito legal ou mesmo uma definição universalmente aceita (UNITED NATIONS REFUGEE AGENCY [UNHCR], 2016).

Os próprios editores do The Oxford Handbook of Refugee and Forced Migration Studies reconhecem que a linha a ser traçada entre refugiados e migração forçada não é consenso, mas que se trata de situações diferentes (JURASZ, 2016).

A imigração interfere diretamente na construção de nova identidade social de um país e, consequentemente, na construção da identidade do indivíduo, seja ele migrante ou nativo de uma nação. As migrações humanas têm papel principal na construção de sociedades híbridas. Com a imigração internacional progressiva, a sociedade multicultural é vigente. Segundo Hall (2003, p. 52), multicultural é:

[...] um termo qualificativo. Descreve características sociais e problemas de governabilidade apresentados por qualquer sociedade na qual diferentes comunidades culturais convivem 
e tentam construir uma vida em comum, ao mesmo tempo em que retêm algo de sua identidade "original".

Sob esse aspecto, a identidade social dos indivíduos e seu desenvolvimento contemplam a sociedade multicultural. Para uma sociedade multicultural, um termo utilizado para caracterizar as culturas cada vez mais mistas é o hibridismo, porém, seu sentido tem sido mal interpretado. Hibridismo "não é uma referência à composição racial mista de uma população. É realmente outro termo para a lógica cultural da tradução" (HALL, 2003, p. 74). Para o autor, hibridismo não se refere aos indivíduos, mas refere-se ao momento de transformação social, do qual a tradução cultural nunca se completa e permanece em desenvolvimento. Conforme Hall (1997), as identidades nacionais estão em declínio e novas identidades híbridas estão tomando o seu lugar. A globalização interfere no multiculturalismo, sendo que a globalização padroniza a forma de se vestir, língua utilizada mundialmente para se comunicar, comida, música etc.

O termo multiculturalismo refere-se "às políticas e estratégias para governar ou administrar problemas de diversidade e multiplicidade gerados pelas sociedades multiculturais" (HALL, 2003, p. 52). Ele possui dificuldades específicas e é caracterizado por articulações, ideais e práticas sociais. O multiculturalismo sempre existiu, ele é tão antigo quanto a humanidade, e tem se intensificado desde a segunda guerra mundial, além de ocupar um lugar destacado no campo político (HALL, 2003). Isso traz sérias mudanças decisivas nas forças e relações sociais de todo o mundo. O encaminhamento das ações ligadas ao multiculturalismo depende da natureza das questões em debate e dos países envolvidos. No caso do Brasil, "leva-se em conta a diversidade étnica e o pluralismo cultural” (D'ADESKY, 1997, p. 165) inclusive na Constituição Federal.

Kymlicka (2012) descreve diversos fatores que interferem na implementação do multiculturalismo. Esses incluem enxergar o multiculturalismo como uma política social ou como questão de segurança de Estado - quando o Estado considera os imigrantes uma ameaça, principalmente aqueles que chegam como refugiados ou ilegais, caso em que o apoio ao multiculturalismo é reduzido.

Um fator que facilita o multiculturalismo é quando existe comprometimento compartilhado em relação aos direitos humanos em todas linhas étnicas e religiosas envolvidas. Nesse caso, se o Estado identifica que determinados grupos (como exemplo, os muçulmanos) não estão dispostos a respeitar as normas democráticas liberais, é pouco provável que conceda direitos ou recursos multiculturais a esse grupo. Um ponto interessante, e destacado por Kymlicka (2012), é que o multiculturalismo funciona melhor quando é genuinamente multicultural, isto é, quando há imigrantes de vários países em vez de um enorme grupo de um mesmo país.

O esforço e contribuição econômica que os imigrantes fazem à sociedade também é um embasamento ao multiculturalismo. Consequentemente, quando as questões facilitadoras estão presentes, o multiculturalismo pode ser visto como uma opção de baixo risco. De qualquer forma, conforme salienta Kymlicka (2012), rejeitar o multiculturalismo de imigrantes, sob circunstâncias de asilo e de entrada ilegal, é um movimento de alto risco porque é, precisamente nessa situação, que o multiculturalismo pode ser mais necessário para dar suporte a essas pessoas.

Somado aos problemas relacionados ao desenvolvimento social devido à diversidade de etnias, ainda há o ressurgimento de traços de antigos nacionalismos étnicos e religiosos mal resolvidos, fazendo com que as tensões nessas sociedades ressurjam de forma multicultural. A exclusão social e a discriminação são alguns traços étnicos permanentes na sociedade. Existe o racismo informal e o institucionalizado, conforme Hall (2003) destaca. Por isso, o racismo é 
existente nas ruas, nas empresas, nos órgãos governamentais e nas instituições. Sob este contexto, um dos aspectos atuais mais problemáticos procedente da imigração e da globalização é a exclusão social. Os aspectos discriminatórios devido à religião e etnia ainda existem e ganham força nessas sociedades que ressurgem sob a forma multicultural. Nesse sentido, destacam-se as pautas dos direitos humanos enquanto centrais à manutenção dos processos democráticos, especialmente "quando neles se introduz o debate sobre o direito das minorias e dos grupos étnicos marginalizados em grandes áreas culturais" (OLIVEIRA; SOUZA, 2011 , p. 123).

A comunidade que recebe o imigrante não está alicerçada numa tradição imutável, da mesma forma que as tradições do indivíduo variam de acordo com a pessoa e constantemente são reformuladas devido à experiência do processo migratório. Trazendo esses aspectos que acarretam constante mudança de identidade social para o universo das organizações, é necessário primeiramente entender que a empresa e as pessoas que as compõem precisam estar preparadas para a diversidade. De acordo com Fleury (2000), o conceito de diversidade na organização está relacionado ao respeito à individualidade dos empregados e ao reconhecimento desta. Respeitar a identidade cultural do funcionário imigrante, a sua diversidade caracterizada pela conduta e comportamento, de acordo com Sarriera, Pizzinato e Meneses (2005), talvez seja o aspecto mais importante a ser conquistado para se viver numa sociedade e organização multiculturais.

Atualmente a ideia de reconhecer e valorizar a diferença dos indivíduos integra o repertório do universo corporativo, como salientam Barbosa e Veloso (2007). Além disso, os autores afirmam que, tanto na esfera política quanto na própria esfera organizacional, a noção de multiculturalismo vai além das políticas identitárias, pois constrói as questões da diferença e da identidade em cima da importância do reconhecimento da diferença, elemento importante tal como reforça Jacques (2006). Esse conceito inclui não só identidades pessoais, mas inclui as políticas multiculturais, os dilemas éticos relacionados à diversidade cultural e étnica, os conflitos interculturais e a questão da integração (individual e social).

Nas organizações, o multiculturalismo é caracterizado pela coexistência de várias identidades sociais no interior de um mesmo espaço de trabalho. Algumas vezes, a necessidade de interação cotidiana é limitada, ou não existe interação entre as pessoas. De acordo com Barbosa e Veloso (2007), para uma empresa alcançar seus objetivos com uma equipe multicultural, faz-se necessário ir além dos aspectos do multiculturalismo e da compreensão da diversidade; é necessária uma base comunicacional comum, onde o diálogo predomine e onde todos compreendam os objetivos do negócio e a melhor forma de atingi-los. Existe a necessidade de se entender o outro de um ponto de vista cultural, para que o diálogo e a comunicação possam ser estabelecidos, ou seja, precisa-se de uma "cultura organizacional com enfoque global" (BUENO; FREITAS, 2015, p. 15). Sodré (2017), por sua vez, sugere que não bastam as políticas afirmativas, mas que são necessárias uma educação e uma aproximação pela afetividade.

\section{AS ENTREVISTAS E OS ENTREVISTADOS}

Trata-se de uma pesquisa qualitativa exploratória que utilizou entrevista e dados demográficos. De acordo com Bauer e Gaskell (2003 ), esse tipo de pesquisa lida com interpretações das realidades sociais. É uma pesquisa empírica, que não utiliza números, mas textos que devem ser interpretados. Como o foco do estudo é verificar de que forma a identidade dos imigrantes vem sendo vivenciada em cidade e organizações multiculturais, definiu-se que a pesquisa ex- 
ploratória é o melhor método para a busca do corpus a ser analisado. A definição do método partiu da necessidade de entender diferentes ambientes sociais e observar conceitos, opiniões, vivências, crenças, sentimentos, identidades, ideologias, religiões e hábitos, através de uma pesquisa qualitativa exploratória. Esse tipo de pesquisa é também uma maneira de dar voz e poder às pessoas, em vez de tratá-las como objeto.

A técnica utilizada de coleta de dados é a entrevista semiestruturada. De acordo com Bauer e Gaskell (2003 ), o foco de uma entrevista não é contar as pessoas/opiniões, mas explorar as opiniões num meio social específico onde haverá diferentes representações sobre o assunto. A entrevista é a vivência do entrevistado e tem como objetivo uma compreensão detalhada das crenças, atitudes e motivações em relação ao comportamento das pessoas num contexto social específico.

Outras vantagens dessa técnica, de acordo com Gil (2008), é que a entrevista não exige que a pessoa entrevistada saiba ler e escrever, possibilita um maior número de respostas (pois é mais fácil negar um questionário do que negar a ser entrevistado), oferece maior compreensão das perguntas (pois o entrevistador pode explicar as perguntas que faz) e ainda possibilita captar a expressão corporal e oral do entrevistado, fator importante e ressaltado por Bauer e Gaskell (2003).

De acordo com o tema pesquisado, foi empregada a técnica de grupos naturais para segmentar os entrevistados. Sabe-se que, nos grupos naturais, as pessoas podem partilhar um passado comum ou ter um projeto futuro comum. Nesta pesquisa, os participantes passaram pela mesma experiência de vivenciar um processo de imigração e estão vivendo na mesma cidade, no caso, Porto Alegre, e que estão no mercado de trabalho (ou tentando entrar). A seleção foi de 8 participantes, pois, conforme Bauer e Gaskell (2003), após a entrevista é necessário analisar o corpus de cada uma, lembrando que, cada uma dessas gera volumosos aspectos a serem analisados.

Tabela 1 - Descrição da Amostra

\begin{tabular}{|c|c|c|c|c|c|c|}
\hline Entrevistado & País & Sexo & Religião & $\begin{array}{l}\text { Mês e Ano de } \\
\text { Imigração }\end{array}$ & $\begin{array}{c}\text { Ano que iniciou } \\
\text { a trabalhar no } \\
\text { Brasil }\end{array}$ & Situação atual \\
\hline E1 & Senegal & Masculino & Muçulmana & nov./2015 & 2015 & Empregado \\
\hline E2 & Senegal & Masculino & Muçulmana & set./2015 & 2015 & Empregado \\
\hline E3 & Haiti & Masculino & $\begin{array}{c}\text { Assembleia } \\
\text { de Deus }\end{array}$ & maio/2014 & 2014 & Desempregado \\
\hline E4 & Haiti & Feminino & Católica & nov./2015 & 2015 & Desempregada \\
\hline E5 & Haiti & Masculino & Protestante & nov./2013 & 2013 & Desempregado \\
\hline E6 & Haiti & Masculino & $\begin{array}{c}\text { Assembleia } \\
\text { de Deus }\end{array}$ & jan./2015 & 2015 & Empregado \\
\hline E7 & Chile & Masculino & Católica & set./1996 & 1996 & Empregado \\
\hline E8 & Peru & Feminino & Católica & mar./2014 & 2014 & Estudante \\
\hline
\end{tabular}

Fonte: Elaborada com dados coletados na pesquisa.

Com esse universo de entrevistados, foi possível obter representações individuais, perceber a interferência da identidade dos indivíduos e verificar os processos sociais e profissionais de cada pessoa. Cada uma das entrevistas teve um tempo médio de uma hora e, elaboradas com 19 perguntas em um roteiro semiestruturado, contemplaram questões sobre: a história de vida dos participantes e o percurso migratório, percepções destes quanto às diferenças culturais e, 
ainda, quanto aos modos de vida no trabalho em relação aos dois países.

A análise e a interpretação dos dados coletados seguiram a técnica da análise de conteúdo. Para iniciar a análise, primeiramente o corpus passa por um processo de codificação. Após, é feita uma leitura no sentido de limpá-los, e o passo seguinte é o de definir unidades de análise por temas (MORAES, 1998 ). Para isso, iniciou-se com a leitura flutuante das entrevistas e, a partir desta, destacaram-se as unidades de significado. No decorrer, cada entrevista foi lida e segmentada pelos temas (significados) existentes. Identificaram-se as principais ideias expressas, sendo possível ordená-las de forma que construam um texto descritivo, apresentadas neste estudo em tabelas, que sintetizam o conteúdo da respectiva problematização inicial. Por fim, apresentam-se extratos de entrevista, retirados diretamente das suas transcrições para formar descrições mais consistentes e realizar a validação de conteúdo.

Para melhor análise dos temas, os entrevistados foram segmentados em dois grupos, sendo o primeiro grupo de migrantes forçados e o segundo grupo de migrantes voluntários, categorias definidas a posteriori da coleta dos dados. Aos haitianos, por exemplo, foram concedidos vistos humanitários em detrimento do status de refugiado (já que não se tratava de perseguição política), em virtude de todas as obrigações do Estado para com os refugiados, como garantias civis, sociais, educacionais e até mesmo trabalhistas. Tratou-se de sugestão do próprio Alto Comissariado das Nações Unidas para Refugiados (ACNUR), pois assim não onerava o governo brasileiro com as obrigações da Convenção de Genebra, mas permitia a esses migrantes uma proteção estatal mínima (UEBEL, 2016). Assim como os haitianos, os senegaleses também são considerados migrantes econômicos (UEBEL, 2015) e fazem parte do primeiro grupo. O segundo é composto por imigrantes do Peru e do Chile.

Tabela 2 - Divisão dos grupos. Países dos entrevistados

\begin{tabular}{ccc}
\hline Grupo & Países & Entrevistados \\
\hline Grupo 1 & Senegal e Haiti & E1, E2, E3, E4, E5 e E6 \\
Grupo 2 & Peru e Chile & E7 e E8
\end{tabular}

Fonte: Elaborada com dados coletados na pesquisa.

É significativo salientar que alguns dados dos entrevistados do Grupo 1 foram invalidados. As habilidades das entrevistadoras nas línguas portuguesa, inglesa e francesa não foram suficientes para uma comunicação efetiva em relação às línguas nativas. Dessa maneira, foram analisados os conteúdos dos entrevistados E1, E2 e E3, do grupo 1, e dos entrevistados E7 e E8 do grupo 2. A unidade de análise foi dividida em três temas que compreendem desdobramentos da problemática desta pesquisa, a saber: identidade social, imigração e multiculturalismo.

\section{ANÁLISE DA IMIGRAÇÃO DE SENEGALESES, HAITIANOS E LATINO-AMERICANOS RESIDENTES EM PORTO ALEGRE}

A primeira categoria analisada foi a identidade sob uma perspectiva social, no que diz respeito à etnia e raça dos entrevistados, a costumes e cultura, e como essas características se fazem presentes no cotidiano, mesmo estando em outro país. A tabela abaixo sintetiza os principais resultados da análise dos dados, dando destaque aos elementos mais referidos pelos entrevistados de acordo com os dois grupos propostos. 
Tabela 3 - Identidade social

A etnia é fator de orgulho para as pessoas destacando pontos positivos como ser
trabalhador e de fácil adaptação ao ambiente.
As festas tradicionais, a comida, a música são fatores culturais importantes e eram
presentes na vida das pessoas no seu país. Sofrem de carência dos costumes no país
migratório.
Sempre que possível os costumes e tradições são continuados no país migratório,
como por exemplo: elaboração dos pratos típicos, escutar música e fazer jejum até o
sol baixar no mês do sacrifício. As celebrações tradicionais são difíceis de manter, pois
necessitam de animais e rituais não possíveis de obter no Brasil.

Fonte: Elaborada com base na análise dos dados coletados na pesquisa.

Os dados do Grupo 1 mostram que a etnia é valorizada, e a raça é relacionada com características comportamentais das pessoas, como ser trabalhador e de fácil adaptação. Tal valorização fala de uma classificação preconceituosa e questionável, uma vez que é temerário classificar etnicamente uma pessoa por características comportamentais, e raça, como mencionado anteriormente, não é uma categoria biológica, mas sim discursiva (PEREIRA; OLIVEIRA, 2017). Conforme relato do E2, "O Senegalês trabalha muito e quer trabalhar, só precisa nos oferecer trabalho". No Grupo 2, a etnia é relatada e comparada quando os valores de vida do seu país são valorizados e contrastados com o do país migratório. Conforme E7 relata:

Eu não gosto da falta de estruturação que o brasileiro tem. O brasileiro vive o hoje e nunca pensa no amanhã. O sucesso, a ideia que o brasileiro tem da vida está na lei dos jogadores de futebol. Brasileiro tem sonhos e não planos.

Hall (1997) argumenta sobre a importância das culturas nacionais em que a pessoa nasce, e que constituem na principal fonte de identidade cultural. Ao fazer autorreferência sobre ser brasileiro, senegalês ou chileno, se está informando, de forma metafórica, algum elemento sobre a identidade, representada aqui como pertencente a uma raça e etnia, fatores que contemplam um Estado-nação. Todos os entrevistados demonstraram verbalmente orgulho e lealdade ao seu país, relatando valores e características de sua nação.

A cultura e os costumes demonstrados na pesquisa têm grande significado na vida dos entrevistados e são comprovados com os relatos de carência desses aspectos no país migratório em ambos os grupos analisados. A comida é o item mais destacado, seguido por festas tradicionais, sendo estas religiosas ou nacionais. Hall (1997, p. 50) afirma que "uma cultura nacional é um discurso, um modo de construir sentidos que influencia e organiza nossas ações e a própria concepção de nós mesmos". Dessa maneira, é reafirmado que fatores culturais como comida, 
celebrações nacionais, música, dança e língua são presentes diariamente na vida das pessoas e são o que faz sentido para a formação de sua identidade social.

Quando a pessoa emigra, a carência desses aspectos é a mais perceptível. A permanência ou tentativa de realizar alguns fatores culturais da sua nação no país migratório (como ter acesso à comida típica, celebrar festas nacionais etc.) é visivelmente comprovada nos relatos do Grupo 1 e 2. Tal fato remete a dois elementos importantes: identidade e memória. É pela memória que o sujeito se constitui (BLEICHMAR, 2005) e o fato de lembrar das comidas e festas já celebradas alimenta a narrativa e construção da vida e memória. Conforme o relato do E8, "Mas mais que tudo, a comida eu sinto muita, muita falta. Agora, em Porto Alegre, tem 2 restaurantes peruanos que, quando eu posso, eu vou, pois realmente a comida eu sinto muita falta." Assim, há, quando possível, a continuidade de seus costumes e cultura no país estrangeiro. Porém Hall (2003) salienta que as tradições são mutáveis, como ocorre nas diásporas, e variam de acordo com a pessoa ou mesmo dentro de uma pessoa, e seguidamente são refletidas, revisadas e transformadas em respostas às experiências migratórias. Compreende-se, assim, a abordagem de que a identidade social do indivíduo é constantemente modificada e reconstruída de acordo com a identidade dos locais onde a pessoa transita, criando então uma nova identidade social.

Isso provoca a pensar também a importância de associar identidade social com relações de trabalho. À medida que o sujeito se insere em um novo mercado de trabalho, novas relações de trabalho também emergem e novas configurações entre os agentes sociais (trabalhadores e empregadores) são apresentadas (FISCHER, 1987), formando uma imagem caleidoscópica das relações de poder emergentes dessa nova configuração.

O segundo tema analisado foi motivo e efeito de migrar, especialmente a existência ou não de discriminação por ser imigrante. A tabela abaixo sintetiza os principais resultados da pesquisa de acordo com a prevalência dos argumentos coletados nas entrevistas individuais.

Tabela 4 - Os motivos e efeitos da imigração

O motivo para migrar foi a busca de melhoria de vida para si e família, devido à situação econômica do seu país. O Brasil foi um país escolhido pelos imigrantes devido às informações não oficiais (amigos) que obtiveram antes de migrar.

Grupo 1 A insegurança e o alto nível de violência são destacados como diferença negativa no Brasil. Assim como a dificuldade financeira, má remuneração e dificuldade de avançar nos estudos.

A discriminação existente foi igualada à de qualquer lugar do mundo. Há pessoas que discriminam e outras não, como em qualquer parte do mundo.

O motivo para migrar foi pessoal, para trabalhar e desenvolver os estudos. O Brasil foi um país escolhido pela oportunidade do emprego/estudo, pela língua e proximidade com país de origem. Fez pesquisas não oficiais e oficiais (sites do governo e estatísticos) para a decisão de migrar ao Brasil.

Grupo 2 A insegurança e o alto nível de violência são destacados como diferença negativa no Brasil. Assim como o desrespeito pelas pessoas devido ao mal planejamento econômico, político e social. A maneira do brasileiro tratar as pessoas no cotidiano, com cuidados e presteza, foi ressaltada.

A discriminação existe e acarretou surpresa por se tratar de um país com tanta miscigenação.

Fonte: Elaborada com base na síntese dos dados analisados na pesquisa. 
O motivo de migrar do Grupo 1 foi a necessidade de dar melhor condição de vida para a família (que ficou no país de origem). Bem diferente dessa necessidade, o Grupo 2 teve como motivo de imigração o desenvolvimento pessoal e profissional, não possuindo necessidade de melhorar de vida por já terem condições muito boas no seu país. Contudo os entrevistados do Grupo 1 relataram que melhorar de vida, para eles, também é ter mais dinheiro e estudar para se desenvolver numa profissão. Esse ponto reflete uma dimensão da ideologia dominante produzida pelas práticas gerencialistas e reproduzida pelos trabalhadores cotidianamente (BENDASSOLLI, 2007). Há uma questão econômica presente no imaginário social, portanto, que serve ao exercício de uma dominação empresarial, conseguindo aliar os desejos humanos às demandas das organizações, sem responsabilizá-las ou ao Estado pela ausência de políticas de educação. Afora isso, esse imaginário social também serve para ressaltar que tanto os diferentes espaços de trabalho quanto as diferentes oportunidades laborais que se apresentam para os imigrantes, vão se constituir em oportunidades diferenciadas para a aquisição de atributos qualificativos da identidade deles e, por vezes, podem tanto qualificar quanto desqualificar os modos de ser dos sujeitos trabalhadores (JACQUES, 2006).

No momento da decisão da migração, todos os entrevistados escolheram o Brasil como país migratório devido às oportunidades. Cabe ressaltar que o Grupo 1 teve informações não oficiais para tomar a decisão de migrar para o Brasil, conforme relata E1: "Na verdade, eu trabalhava no Senegal. E lá muita gente fala que o Brasil é bom para trabalhar e que ganha mais aqui do que no Senegal." Um dos entrevistados do Grupo 2 (E8) fez ampla pesquisa sobre custos de vida, como é a cultura e estudou a língua anteriormente. Já o entrevistado E7 (do Grupo 2) buscou o Brasil devido à oportunidade de trabalho e relatou que o motivo de migrar foi por ter saído do seu país 4 anos antes (para fazer doutorado) e, quando retornou, não reconheceu a cultura do seu país:

Quando eu parti, em 1989, Chile era uma ditadura militar. Nesta época, eu e meus amigos estávamos todos no final de seus estudos. Quando eu retornei, tínhamos uma democracia e tudo era diferente. Meus amigos eram na grande maioria homens casados. Para, mim foi um choque. (E7).

Algumas constatações dos motivos de migrar são as mesmas que Hall (2003) elucida sobre a pobreza, o subdesenvolvimento e a falta de oportunidades serem alguns fatores que forçam a pessoa a migrar, além de guerra, desastres naturais, repressão política etc., esclarecendo que a migração e o deslocamento fazem parte da história dos povos. Assim, percebe-se que os motivos, independente da época de imigração, se repetem. Também nota-se que uma nação certamente sofre interferência de outras culturas. Outro ponto a refletir é sobre a decisão de migrar devido ao não reconhecimento do seu país após experiência de migração anterior, conforme relatou E7. Para Hall (2003), esta é uma sensação familiar e moderna do deslocamento e que não é preciso viajar muito longe para experimentar. Assim, muitos imigrantes não reconhecem a identidade social de seu país quando retornam e têm a sensação de não pertencer mais à nação. Se a memória diz também sobre a identidade de uma pessoa (BLEICHMAR, 2005), pode-se imaginar o sofrimento de um indivíduo quando perde os laços e a sensação de não pertencimento ao seu lugar de origem, tal como relata E7.

Porém, apesar da interferência de outras culturas, cada país possui a sua, e foi instigante analisar se as diferenças culturais interferem de forma destacada na vida dos imigrantes. De acordo com os entrevistados de ambos os grupos, a falta de segurança foi característica destacada e de grande surpresa para eles, inclusive para o entrevistado que pesquisou sobre o Brasil. Além 
disso, grande parte dos entrevistados querem retornar ao seu país de origem, por afirmarem ter se decepcionado com o Brasil, seja pela promessa não conquistada de postos dignos de trabaIho, seja pela discriminação recorrente. Isso também talvez ocorra já que é possível que "cada disseminação carregue consigo a promessa do retorno redentor" (HALL, 2003, p. 28).

A discriminação foi outro fator analisado. De acordo com as entrevistas, o grupo 1 não sofreu discriminação no Brasil de forma que sobressaísse a outros países. Já no grupo 2, há um relato sobre discriminação, em que o entrevistado argumentou que, por falar outra língua, uma pessoa na rua o discriminou por estar "tirando" trabalho de um brasileiro. Nesse caso, a discriminação não foi devido à raça ou etnia, mas por ser imigrante. Essa análise pode ser incorporada à explanação de Hall (2003) sobre a discriminação relativa ao imigrante, pois ele defende que tanto o racismo biológico quanto a discriminação cultural não constituem dois sistemas distintos, mas dois registros do racismo. Dessa forma, a discriminação demonstrada no relato do entrevistado é cultural, somada à situação de falta de emprego que o Brasil enfrenta.

O terceiro tema analisado foram as questões do multiculturalismo no Brasil e nas organizações. Destacaram-se os fatores como recepção ao chegar no Brasil e nas organizações/instituições, convívio no ambiente multicultural, amizade e vida social. A tabela seguinte, da mesma forma das anteriores, destaca os principais achados analíticos.

Tabela 5 - Multiculturalismo e as diferenças culturais

A recepção foi boa, porém houve falta de informações sobre quais procedimentos deveriam ser seguidos. Sempre foram bem tratados pelos brasileiros.

São criadas colônias de imigrantes, o que resulta em dificuldade de conhecimento e inserção na cultura local. A língua é aspecto relevante para a inserção na cultura.

Grupo 1 Grande parte dos amigos é imigrante, com exceção de alguns casos. Não há interação e conhecimento sobre eventos culturais por não ter acesso à cultural local.

As organizações recepcionam e aceitam bem os imigrantes, a língua é o problema de comunicação para se obter trabalho. Existe tendência de remuneração mais baixa por ser imigrante.

Houve sempre boa recepção por parte de brasileiros

Aprender a língua portuguesa é essencial para convivência.

Existe boa receptividade dos brasileiros quanto ao imigrante para a vida social. Os amigos

Grupo 2 são, em grande parte, imigrantes mas possuem amigos brasileiros.

As organizações e instituições recepcionam e administram bem o imigrante por já falarem o português. Os colegas criam grupos fechados de trabalho onde excluem os imigrantes, estes acreditam que são devido à fatores culturais, de língua e formação educacional.

Fonte: Elaborada pelo autor com base na síntese dados analisados na pesquisa.

Ao analisar as entrevistas, foi apurado que os brasileiros recepcionam bem os imigrantes na chegada ao país. O Grupo 1 teve algumas dificuldades em ter acesso à informação sobre aspectos legais, como: onde ir para buscar documentos, como proceder, quanto tempo de espera, etc. Porém essas dificuldades se deram também devido aos imigrantes não falarem a língua portuguesa nem a língua inglesa. Já o Grupo 2 não relatou qualquer dificuldade e os entrevistados informaram que foram bem recebidos. Aliás, essa característica de bem recepcionar o estrangeiro foi uma grata surpresa para todos os imigrantes. 
Percebi que as pessoas viam que eu não era do Brasil e eram mais atentas comigo, alegres e perguntando o que eu precisava. Teve uma mulher que perguntou o que eu estava precisando e me levou até a Polícia Federal. Aqui no Peru isso seria muito estranho, nós somos desconfiados com as pessoas e no Brasil não...eu pensava o que estas pessoas queriam pois elas não me conheciam. Eu achava muito estranho. Além disso, na parada de ônibus, quando eu cheguei, fiz uns 2 ou 3 amigos que até hoje eu falo. (E7).

Para Hall (2003), uma nação multicultural é caracterizada por diferentes comunidades que tentam construir uma vida em comum. Ao recepcionar, ajudar e orientar os imigrantes, os brasileiros se revelam abertos aos estrangeiros. Entretanto, a análise realizada sobre a amizade, vida social e convívio no Brasil mostra que o Grupo 1 tem uma colônia separada dos brasileiros e que, apesar de viver nesse país, não possuem uma vida em comum com os brasileiros. Diferentemente do que informa o teórico como característica multicultural, os imigrantes não conhecem a cultura brasileira e não têm acesso a ela, pois a maioria não sabe a língua portuguesa e não tem amigos brasileiros. Desse modo, eles vivem "isolados". Um dos entrevistados afirma: "Não posso falar da cultura brasileira, pois não conheço. Vivo no bairro com imigrantes, no trabalho tinha poucos colegas brasileiros, tinha bem mais amigos imigrantes" E2. Essa perspectiva, por si só, reflete a segregação dos imigrantes, especialmente ao Grupo 1, demonstrando a pouca receptividade da sociedade local quanto à integração do 'diferente'. Além disso, o grupo 1 menciona que existe tendência de remuneração mais baixa por ser imigrante. Tal fato é recorrente no Brasil com imigrantes, especialmente com mulheres, já revelou o estudo de Pereira e Oliveira (2017).

Mais uma vez, a língua destacou-se por ser essencial para permear a cultura local, o que aparece mais forte nos migrantes forçados, que é o Grupo 1, provavelmente por não terem tido tempo ou condições de se preparar para migrar. O Grupo 2, conforme referido, domina a língua portuguesa, conhece muitos aspectos culturais, participa de festas tradicionais e possui amigos estrangeiros e brasileiros. Está, assim, mais integrado ao país e podendo ter a experiência de viver num país multicultural, onde as comunidades culturais convivem e tentam construir juntos uma vida em comum, como Hall (2003) defende, apesar de isso não acontecer com o grupo de migrantes forçados. A possibilidade de acolhimento desse imigrante pelos brasileiros apresenta-se como um fato sobretudo humano relacionado ao trabalho. O trabalho, por vezes, por si só, já é carregado de precarização; torná-lo mais humano e com momentos de acolhimento a esse trabalhador, que já vem de uma história de sofrimento e solidão, pode fazer a diferença na trajetória de vida pessoal e profissional desses imigrantes.

Parte-se da premissa de que "traços culturais brasileiros podem influenciar na maneira pela qual as pessoas são percebidas, geridas, administradas e controladas" (MOTTA; ALCADIPANI; BRESLER, 2001, p. 61). Assim, em relação ao multiculturalismo nas organizações, ambos os grupos apresentaram grandes problemas para serem recebidos pelas empresas e instituições. Para o Grupo 1, o fator de não falar a língua é um problema para obter trabalho, bem como para negociar a sua permanência na atividade desenvolvida, havendo relatos de discriminação e violência verbal no tratamento do superior. O Grupo 2, apesar de os entrevistados se sentirem inseridos e aceitos na cultura local, no momento de desenvolverem atividades no trabalho, há uma exclusão, por parte dos colegas, por serem imigrantes.

Os grupos são muitos fechados, eles (colegas) gostam de nós (imigrantes), de mim e uma amiga estrangeira, para as festas, mas são fechados para o trabalho. Imagino que deve ser complicado pra eles para trabalhar com conflito de culturas e personalidades diferentes e percebi que não estão tão abertos para trabalhar com pessoas de outra cultura. (E8). 
Dessa forma, a fala deixa transparecer que há contato nas relações pessoais, de cunho íntimo, mas que encontra dificuldades quando se trata de uma valorização profissional, por vezes até movida pelo sentimento de que o imigrante estaria ocupando um lugar que não é de seu direito. Assim, há um indicativo de que o trabalho avança a fronteira da posição de turista, marcando uma outra posição ao imigrante, limite este que faz com que o grupo crie dificuldades de reconhecimento. De acordo com Hall (2003), com o multiculturalismo, existe a demanda por igualdade e justiça social contra um racismo diferenciado. Além disso, existe a demanda pelo reconhecimento da diferença cultural. Todos esses fatos corroboram com análise desta pesquisa. Já no contexto organizacional, esta demanda também é existente. Fleury (2000) expõe a necessidade de igualdade social como conceito de diversidade, salientando a relação da diversidade com o respeito à individualidade dos trabalhadores.

\section{CONSIDERAÇÕES FINAIS}

Inicialmente, a língua demonstrou-se característica primordial do impasse com a cultura local para que o imigrante possa ser inserido na sociedade, mesmo que esta tenha marcas híbridas de processos migratórios significativos ao longo da história. Nesse sentido, políticas públicas, iniciativas de movimentos sociais e das organizações formais de trabalho que focassem no ensino da língua portuguesa como forma de inserção social, pretendem cumprir com uma importante lacuna desse processo de inclusão.

A raça e etnia são motivos de reflexão e compreensão ao olhar o outro, já que, ao nascer num país, obtém-se a identidade social desse país, mas, muitas vezes, é preciso um árduo movimento para conquistar o efetivo direito de pertencer ao espaço que é considerado do outro. A identidade de nascimento faz parte do "eu social", ao dizer que se é brasileiro como critério de delimitação de si, por exemplo. Contudo a identidade não é engessada e muda de acordo com o ambiente e as vivências que se adquirem no decorrer da vida, inclusive pela possibilidade de pertencimento intencional a um ou mais espaços de Estado-nação.

Por outro lado, sublinha-se que o indivíduo credita importância à comprovação de fazer parte de uma etnia e raça para não "perder" sua identidade. Por isso, a cultura e os costumes em um país migratório são os aspectos mais relevantes e destacados nas narrativas cotidianas dos entrevistados. Conclui-se, portanto, que a língua, a comida e o modo de viver do Estado-nação causam um sentimento de falta ao imigrante e são muito mais importantes do que ele previamente poderia pensar, apesar de se traduzir, em grande parte, em elementos considerados simplórios. No entanto eles dizem respeito especialmente à memória, que nos constitui como sujeitos e faz parte da nossa narrativa da vida. Observa-se, nesse sentido, que a real importância da cultura nacional para um indivíduo só é efetivamente percebida em sua dimensão quando ele deixa de tê-la no seu cotidiano, reconhecendo como as atitudes simples do cotidiano Ihes são realmente representativas. Apesar disso, a ausência da cultura nacional oferece a oportunidade para que os costumes do indivíduo se modifiquem, devido à interferência e à absorção das tradições e da cultura do país migratório. Percebe-se, claramente, a interferência da identidade social do país migratório na construção de uma outra identidade social do imigrante. Dessa maneira, uma pessoa torna-se um indivíduo híbrido e um sujeito com identidade social multicultural, de maior complexidade do ponto de vista das diferenças, que aquela anterior ao processo migratório.

Este estudo também identificou que, pela seleção dos participantes, os motivos de migrar são os mesmos, independente da época. Isto é, o motivo que trouxe os italianos, alemães e 
poloneses ao Brasil, e especial ao RS, no século XVIII, são os mesmos que atraíram os haitianos e senegaleses hoje em dia, que é a busca de melhoria na qualidade de vida. O curioso é que muito do racismo e da xenofobia parte dos descendentes desses imigrantes europeus, normalmente mascarados pelo discurso de suposta superioridade, que é reflexo da dialética das relações raciais em que há a dominação do Norte (IANNI, 2004). Todos esses fatos contribuem para deixar o trabalho mais desumano.

A questão de imigrar e não reconhecer o país de origem e sua cultura após o retorno, não se reconhecer como indivíduo pertencente à nação de origem, é outro fator que oportuniza um aprofundamento de estudo. Se o indivíduo não viver a mudança do seu país (no campo político, social, econômico), acaba tendo um sentimento de desconhecimento, já que os tópicos linguísticos que circulam no social podem não fazer mais sentido nesse espaço de socialização que antes era naturalizado. Dessa forma, a cultura pode ser entendida como bidirecional e (re) construída ao longo da vida dos indivíduos.

Considera-se que o Brasil é um país multicultural, justamente por possuir diferentes comunidades culturais que convivem juntas (como a comunidade formada pelo Grupo 1, por exemplo) e buscam construir uma vida em comum, especialmente afetiva, embora preservando aspectos da sua identidade nacional de origem. Os grupos de imigrantes forçados sofrem com a falta de inserção nos costumes e cultura locais, um fator a ser pensado e desenvolvido pelo governo e pelas organizações de trabalho em relação ao multiculturalismo, haja vista que a falta de diversidade cultural existente numa organização ou instituição acarreta uma certa discriminação. As pessoas que trabalham numa organização ou instituição, aceitam os imigrantes no quadro de funcionários, mas há exclusão no momento de executar as atividades. No assunto em questão, é preciso debater o tema da diversidade dentro das organizações e melhorar as estratégias e regras relacionadas ao multiculturalismo para que o imigrante se sinta integrado ao grupo. Além disso, o diálogo aliado a uma clara comunicação interna nas empresas é um caminho mostrado como essencial para organizações multiculturais. A dificuldade a ser enfrentada pelas organizações privadas de trabalho é criação de uma cultura organizacional na qual a diversidade seja respeitada e aceita como uma característica que possa agregar, inclusive, valor comercial à empresa.

Constata-se um verdadeiro paradoxo: as pessoas querem ser multiculturais e viver com a diversidade, mas relutam em conviver e aceitar a cultura, a religião e a cor de pele das pessoas. Reforçando o que discutimos, e amparados em Sodré (2017), não existe identidade racial, e as discussões sobre raça são eminentemente uma categoria discursiva (PEREIRA; OLIVIERA, 2017). Por isso, o multiculturalismo precisa ser tratado no sentido de buscar responder a uma lacuna nas relações sociais da contemporaneidade no que diz respeito ao debate sobre a discriminação. Seja por parte do Estado, das organizações formais, dos veículos midiáticos ou dos movimentos sociais, ainda é visível a necessidade de ampliar o diálogo sobre as imigrações para buscar o entendimento e a aceitação de outras culturas, de modo a formar um modelo de Estado-nação efetivamente multicultural.

\section{REFERÊNCIAS}

BAENINGER, Rosana et al. Imigração haitiana no Brasil. São Paulo: Paco Editorial, 2017.

BARBOSA, Lívia; VELOSO, Letícia. Gerência intercultural, diferença e mediação nas empresas transnacionais. Civitas - Revista de Ciências Sociais, Porto Alegre, v. 7, n. 1, p. 59-85, jan./jun. 2007. 
BAUER, Martin; GASKELL, George. Pesquisa qualitativa com texto, imagem e som. 2. ed. Petrópolis, RJ: Vozes, 2003.

BENDASSOLLI, Pedro Fernando. O mal-estar na sociedade de gestão - e a tentativa de gestão do malestar (Prefácio). In: GAULLEJAC, Vincent de. Gestão como doença social: ideologia, poder gerencialista e fragmentação social. Aparecida, SP: Idéias \& Letras, 2007.

BLEICHMAR, Silvia. La subjetividad en riesgo. 1. ed. Buenos Aires: Topía, 2005.

BUENO, Janaína Maria; FREITAS, Maria Ester de. As equipes multiculturais em subsidiárias brasileiras de multinacionais: um estudo de casos múltiplos. Organizações \& Sociedade, Salvador, BA, v. 22, n. 72, p. 15-34, jan./mar. 2015.

D'ADESKY, Jacques. Pluralismo étnico e multiculturalismo. Afro-Ásia, n. 19-20, p. 165-82, 1997.

DE OLIVEIRA, Eliane; DE SOUZA, Maria Luiza. Multiculturalismo, diversidade cultural e direito coletivo na ordem contemporânea. Direito, v. 3, n. 16, p. 121-39, 2015.

FIALKOM, Jaime Carrion. Migração internacional contemporânea: principais processos. Panorama Internacional - FEE, Porto Alegre, v. 1, n. 3, p. 8-11, mar. 2016.

FISCHER, Rosa Maria. Pondo os pingos nos "is": sobre as relações do trabalho e políticas de administração de recursos humanos. In: FLEURY, Maria Tereza; FISCHER, Rosa Maria (Coord.). Processo e relações do trabalho no Brasil. São Paulo: Atlas, 1987.

FLEURY, Maria Tereza L. Gerenciando a diversidade cultural: experiências de empresas brasileiras. RAE Revista de Administração de Empresas, São Paulo, v. 40, n. 3, p. 18-25, jul./set. 2000.

GARCEZ, Gabriela Soldano; OLIVEIRA, Meilyng Leone. Multiculturalismo, interculturalidade e direitos humanos: a responsabilidade da mídia em informar para a educação intercultural. Leopoldianum, Santos, SP, v. 40, n. 113-5, p. 7-20, 2016.

GIL, Antônio Carlos. Métodos e técnicas de pesquisa social. 6. ed. São Paulo: Atlas, 2008.

GUIMARÃES, Antônio Sérgio Alfredo. Como trabalhar com 'raça' em sociologia. Educação e Pesquisa, São Paulo, v. 29, n. 1, p. 93-107, jan./jun. 2003.

HALL, Stuart. Da diáspora: identidades e mediações culturais. Belo Horizonte: Editora UFMG, 2003.

Quem precisa da identidade? In: SILVA, Tomaz Tadeu da (Org.). Identidade e diferença: a perspectiva dos estudos culturais. Petrópolis, RJ: Vozes, 2000. p. 103-33

A identidade cultural da pós-modernidade. 10. ed. São Paulo: DP\&A, 1997.

IANNI, Octavio. Dialética das relações raciais. Estudos Avançados, São Paulo, v. 18, n. 50, p. 21-30, jan./ abr. 2004.

JACQUES, Maria da Graça Corrêa. Identidade e trabalho. In: CATTANI, Antônio David; HOLZMANN, Lorena (Org.). Dicionário de trabalho e tecnologia. Porto Alegre: Ed. da UFRGS, 2006.

JURASZ, Olga. Book reviews. International Journal of Refugee Law, v. 28, n. 2, p. 347-61, 2016.

KYMLICKA, Will. Multiculturalism: sucess, failure, and the future: transtlantic council on migration. February 2012. Tradução de Maria Tereza Amodeo. Interfaces Brasil/Canadá, Canoas, RS, v. 14, n. 18, p. 123-74, 2014.

MIRANDA, Antônio et al. Sociedade da informação: globalização, identidade cultural e conteúdos. Ciência da Informação, Brasília, v. 29, n. 2, p. 78-88, maio/ago. 2000.

MORAES, Roque. Uma experiência de pesquisa coletiva: introdução à análise e conteúdo. In: GRILLO, Marlene Correro; MEDEIROS, Marilú Fontoura de (Org.). A construção do conhecimento e sua mediação metodológica. 1. ed. Porto Alegre: EDIPUCRS, 1998. p. 111-29.

MOTTA, Fernando C. Prestes; ALCADIPANI, Rafael; BRESLER, Ricardo B. A valorização do estrangeiro como segregação nas organizações. Revista de Administração Contemporânea, Curitiba, PR, v. 5, número especial, p. 59-79, 2001. 
PEREIRA, Flávia Oliveira; OLIVEIRA, Josiane Silva. A intersecção entre raça, gênero e imigração no mercado de trabalho: um estudo com mulheres haitianas na cidade de Maringá, Paraná. Trabalho apresentado no VI ENCONTRO DE GESTÃO DE PESSOAS E RELAÇÕES DE TRABALHO. Curitiba, 2017.

ROLNIK, Sueli. Toxicômanos de identidade: subjetividade em tempo de globalização. In: LINS, Daniel (Org.). Cultura e subjetividade: saberes nômades. Campinas, SP: Papirus, 1997. p. 19-24.

SARRIERA, Jorge Castellá; PIZZINATO, Adolfo; MENESES, María Piedad Rangel. Aspectos psicossociais da imigração familiar na Grande Porto Alegre. Estudos de Psicologia, Natal, RN, v. 10, n. 1, p. 5-13, 2005.

SODRÉ, Muniz. Raça como fraude civilizatória. Palestra proferida em ocasião da gravação do filme "Depois de ser cinza", Fundação Iberê Camargo, Porto Alegre, 2017.

Claros e escuros: identidade, povo e mídia no Brasil. Petrópolis, RJ: Vozes, 2015.

UEBEL, Roberto Rodolfo Gearg. A mudança da política externa brasileira para imigrantes e refugiados: o caso da imigração haitiana no início do século. Barbarói, Santa Cruz do Sul, RS, edição especial, n. 47, p. 22-43, jan./jun. 2016.

. Análise do perfil socioespacial das migrações internacionais para o Rio Grande do Sul no início do século XXI: redes, atores e cenários da imigração haitiana e senegalesa. 2015. Dissertação (Mestrado em Geografia) - Instituto de Geociências, Programa de Pós-Graduação em Geografia, Universidade Federal do Rio Grande do Sul (UFRGS), Porto Alegre, 2015.

UNITED NATIONS REFUGEE AGENCY (UNHCR). Refugees' and 'Migrants. 16 mar. 2016. Disponível em: <http://www.unhcr.org/afr/news/latest/2016/3/56e95c676/refugees-migrants-frequently-askedquestions-faqs.html>. Acesso em: 13 jun. 2017.

WOODWARD, Kathryn. Identidade e diferença: uma introdução teórica e conceitual. In: Identidade e diferença: a perspectiva dos estudos culturais. In: SILVA, Thomaz T. da (Org.). Petrópolis, RJ: Vozes, 2000.

\section{Sobre os autores:}

Lisiane Selaimen Heemann Ketzer: Especialista em Gestão de Pessoas pela UniRitter Laureate International Universities. E-mail: lisi.heemann@gmail.com

Julice Salvagni: Pós-Doutora pelo Programa Nacional de Pós-Doutorado da Coordenação de Aperfeiçoamento de Pessoal de Nível Superior (PNPD/CAPES). Doutora em Sociologia pela Universidade Federal do Rio Grande do Sul (UFRGS/CAPES). Mestre em Ciências Sociais pela Universidade do Vale do Rio dos Sinos (Unisinos), Especialista em Gestão Empreendedora (Ftec) e Psicóloga (Unisinos). E-mail: julicesalvagni@gmail.com

Andrea Poleto Oltramati: Doutorado em Administração pela Universidade Federal do Rio Grande do Sul (UFRGS).Professora adjunta da UFRGS. E-mail: andreaoltr@gmail.com

Daiane Boelhouwer Menezes: Doutorado em Ciências Sociais pela Pontifícia Universidade Católica do Rio Grande do Sul, Analista Pesquisadora do Núcleo de Políticas da Fundação de Economia e Estatística. E-mail: daianebmenezes@gmail.com 